\title{
Modeling of Monomer Pressure Evolution in an Inductively Coupled pulsed plasma deposition of aniline
}

\section{Ashish Kumar shukla, Rajendra Kumar}

\begin{abstract}
A model has been developed to predict the evolution of monomer pressure over time in an inductively coupled plasma reactor. The model proposes a two-step deposition mechanism: dissociation of monomer by electron collisions fast and $\breve{Z}$. subsequent slow diffusion of radicals toward the substrate. A free radical mechanism is proposed and the dissociation rate Ž. constant is calculated based on the best available cross section information. The model uses an analogous electrical circuit to predict preplasma gas flow conditions. Based on the monomer pressure model, a relationship between pressure prior to electrical discharge and the corresponding plasma polymerized acetylene deposition rate was measured experimentally. A plot of measured deposition rate versus preplasma monomer pressure was observed to have a relative maximum.
\end{abstract}

Index Terms - PECVD, plasma polymerization, plasma poly-merized acetylene film, pressure effects, pulsed plasma.

\section{INTRODUCTION}

PLASMA polymerization is an important technique for the deposition of thin polymer films. At the present time, the continuous plasma discharge is most commonly used in industry. Pulsed-plasma deposition, however, offers significant advantages in terms of improved control of the process and film structure. Additional savings are possible through reductions in energy consumption, raw material usage, and process emissions. One of the challenges in pulsed-plasma processes is the extended run time required for producing films with significant thickness. This problem could be overcome by maximizing the film deposition rate.

Manuscript revised June 10, 2019 and published on July 10, 2019

Ashish Kumar shukla, Research Scholar Department of Physics, Faculty of Engineering \& Technology, Rama University, Kanpur-209217, U.P. INDIA.

Rajendra Kumar Associate Professor Department of Physics, Faculty of Engineering \& Technology, Rama University, Kanpur-209217, U.P. INDIA
Earlier investigations have shown that deposition rate is a strong function of monomer pressure [1]-[6]. For example, it has been observed in continuous plasma reactors that as pressure is increased deposition rates reach a maximum and then plateau or decrease [1], [5], [6]. This phenomenon was explained by assuming a change in deposition mechanism occurs above a certain pressure leading to an increased particle formation in the gas phase [5], [7]. Furthermore, Tsai [3] found a very high particle formation rate at lower pressures $(<$ 0.8 torr) while producing powder-free films at pressures between 0.8 and 1.2 torr. Kobayashi observed powder formation at low pressures in a capacitive coupled reactor [8]. Yasuda points out that these inconsistencies are due to the differences in reactor configuration and power.

Input/mole of gas. Nevertheless, several studies have shown that at constant power smooth films can be formed at high pressure and powder can be formed at low pressure [3]. This indicates that powder formation does not necessarily account for reduced deposition rate at higher pressures.

While pressure is one of the most important parameters in plasma deposition, its effects on deposition rate and film proper-ties have not been investigated in depth in the pulsed-plasma literature. The short time-scales involved in pulsed reactors make it difficult to accurately measure the pressure before plasma initiation. Thus, a model was developed to predict the evolution of monomer pressure with time. Using this model the relationship between deposition rate and monomer pressure in the reactor was investigated experimentally. A fast ionization gauge (FIG) has been used in the past to measure pressure on the time scale of several milliseconds [9], [10]. The use of a FIG is tedious and is restricted to the low-pressure range $(<10$ 0 millitorr). A model was therefore developed to predict reactor pressure as a function of time. The model was validated with measurements performed with a FIG in the low-pressure range. 


\section{International Journal of Research in Advent Technology, Vol.7, No.6, June 2019 E-ISSN: 2321-9637 \\ Available online at www.ijrat.org}

\section{EXPERIMENTAL SETUP}

A tubular Pyrex reactor [Fig. 1(a)], $10 \mathrm{~cm}$ in diameter was used as the deposition chamber in our work. Acetylene or air was pulsed into the reactor using a conventional automotive fuel injector controlled by a computer. A local fuel injector plenum stored gas for "instantaneous" injection into the reactor while the remote plenum replenished the local plenum on a slower time-scale [see Fig. 1(b)]. Plasma was generated using a single turn inductively coupled RF coil as shown in Fig. 1(a). Discharging a $1.86-\mu \mathrm{F}$ capacitor (with initial voltage equal to $23 \mathrm{kV}$ ) into the RF coil produced each plasma pulse. Excitation voltage at the RF coil had a time dependence that can be described as a damped sinusoid with maximum value $23 \mathrm{kV}$, fundamental frequency $290 \mathrm{kHz}$, and a decay time constant of about $10 \mu_{\mathrm{S}}$. The repetition rate for injection of acetylene and RF energy was one run per minute. For this work, each run consisted of one monomer injection pulse, one RF energy injection event and one complete evacuation of the reactor by the vacuum pump. A typical film was synthesized by exposing the substrate and the growing film to 50 of these runs.
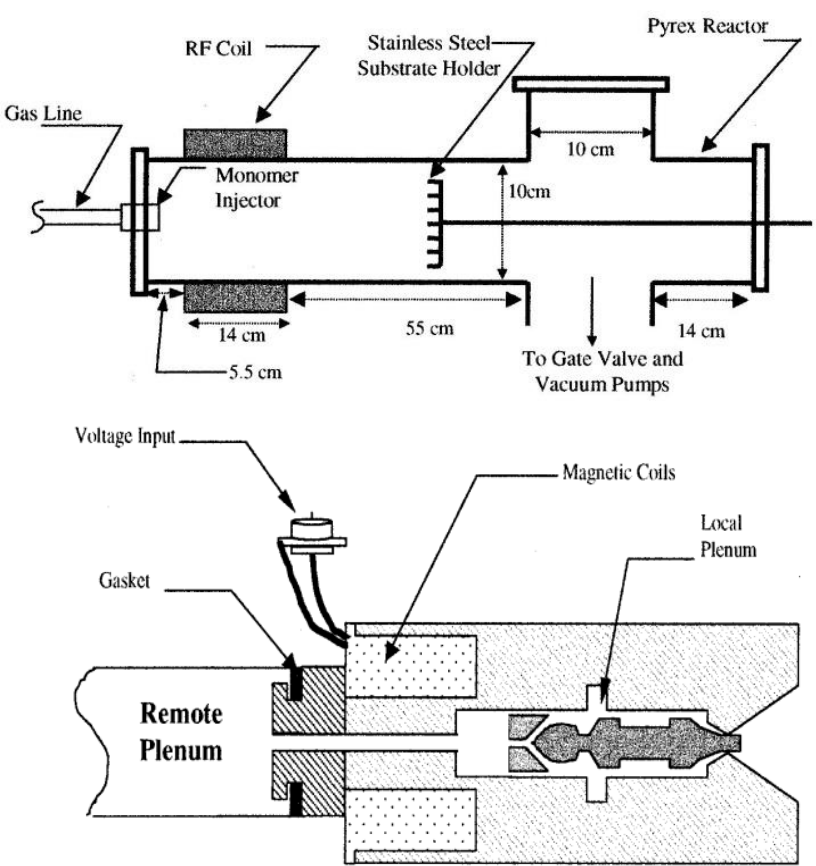

Fig. 1. Drawings of (a) plasma reactor and (b) pulsed gas injector

A computer was used to control [11] the duration of the gas pulse and the delay time between feed material injector activa-tion and RF coil activation. The duration of the gas pulse was determined approximately by the time interval for which voltage $(12 \mathrm{~V} \mathrm{dc})$ was applied at the "voltage input" terminal shown in Fig. 1(b). For this work, the gas pulse duration was typically in the range 10 to $50 \mathrm{~ms}$. A diffusion pump in series with a roughing pump maintained reactor base pressure of $5 \times 10_{-5}$ Torr. Pump-down could be halted at any time by closing a gate valve isolating the chamber from the vacuum pumps. Silicon wafers with a $1000 \AA$ layer of $\mathrm{SiO}_{2}$ were cut into pieces of suit-able size and were used as substrates. These substrates were mounted normal to flow onto the seven-fingered metal stage [Fig. 1(a)]. The metal stage was insulated from ground so that its electrostatic potential tracked the floating potential of the plasma. Plasma polymerized film thickness was measured with a Tencor Alpha Step 200 Model 1002000 Profilometer and con-firmed with a Digital Instruments Model MMAFM-2 Atomic Force Microscope.

The fast ionization gauge used in this work has been described earlier [10]. The sensitivity factor for this fast ionization gauge is given by Ueda [12]. As in Ueda's work, a 6AU6A vacuum tube with $40 \%$ of the plate removed was used here. Removal of plate material allows gas to flow unhindered into the ionization region. Ueda's measurements were for molecular hydrogen and a curve fit to his data gives

$n H_{2}=\left(2.769 \times 10^{23}\right) I^{1.042}$

Hear $n H_{2}$ is gas concentration in $\mathrm{m}^{-3}$ and collector current in amperes. Tate and Smith [13] reported that for $100 \mathrm{eV}$ electrons the ionization efficiency for acetylene is 5.13 times larger than that for hydrogen. Using this fact together with the empirical relation for molecular hydrogen (1) the relationship for acetylene, $\mathrm{C}_{2} \mathrm{H}_{2}$ is estimated as

$$
\begin{aligned}
n C_{2} H_{2} & =\left[\frac{\left(2.611 \times 10^{24}\right)}{(5.13)} I\right]^{1.042} \\
& =\left(5.039 \times 10^{24}\right) I^{1.042}
\end{aligned}
$$

In arriving at (2), we have assumed that the 5.13 times larger ionization efficiency for acetylene will create 5.13 times more cur-rent at a given molecular number density; therefore, the constant that gets multiplied times current in (1) is divided by the factor 5.13 when the FIG is used in acetylene. Equation (2) was used to convert the measured fast ionization gauge current to acetylene number density. The ideal gas law was then 


\section{International Journal of Research in Advent Technology, Vol.7, No.6, June 2019 \\ E-ISSN: 2321-9637 \\ Available online at www.ijrat.org}

used to convert this density to the equivalent static pressure at STP giving

$\mathrm{P}_{\text {STATIC }}, \mathrm{H}_{2}=(860) \mathrm{I}^{1.042}$

$\mathrm{P}_{\text {STATIC }}, \mathrm{C}_{2} \mathrm{H}_{2}=(157) \mathrm{I}^{1.042}$

Where current $I$ is in amperes and pressure $P$ is in Torr. Finally, using the ionization gauge sensitivity ratio of Nakao [14], the calibration equation for this fast ionization gauge in air is

$$
P_{\text {StATIC }}, \text { Air }=(3777) \mathrm{I}^{1.042}
$$

\section{TRANSIENT PRESSURE MODEL}

To predict preplasma pressure in the reactor as a function of time, a model was developed using an analogous electrical circuit [15]. In addition to accurately predicting variation of preplasma pressure in the reactor with time, the model is also applicable to other unsteady flow reactors. Pressure and gas flow phenomena in the reactor can be modeled with the analogous electrical circuit depicted in Fig. 2. In the model, voltage $\left(\mathrm{V}_{0}, \mathrm{Vpl}, \mathrm{V}_{1}, \mathrm{~V}_{2}\right)$ represents pressure, capacitance $\left(\mathrm{C}_{\mathrm{pl}}, \mathrm{C}_{1}, \mathrm{C}_{2}\right)$ represents volume and resistance $\left(\mathrm{R}_{\mathrm{pl}}, \mathrm{R}_{1}, \mathrm{R}_{2}\right)$ represents resistance to gas flow. Table I shows how the circuit elements in Fig. 2 correspond to the gas flow parameters. $\mathrm{C}_{1}, \mathrm{C} 2$, and $\mathrm{C}_{\mathrm{pl}}$ values were either measured or were easily calculated from reactor dimensions. The value of the capacitor $\mathrm{C}_{\mathrm{pl}}$ that is analogous to the remote plenum volume varied de-pending on the setup. For example, when using acetylene the volume of the remote plenum was measured to be $3.4 \times 10^{-5} \mathrm{~m}^{3}$. For experiments with air, the remote plenum was exposed to room air and its volume was assumed to be infinite. Resistance values in Table I were calculated as explained below.

Time-dependent pressure in the remote plenum, in the local plenum and in the reactor chamber in Fig. 1 are found by solving for the time-dependent voltages $\mathrm{V}_{\mathrm{pl}}$, $\mathrm{V}_{1}$ and $\mathrm{V}_{2}$ in Fig. 2. These three time-dependent voltages can be found by analyzing the circuit in Fig. 2 using a software package such as HSPICE [16] or by directly solving the differential equations that result from nodal analysis.

$\frac{V_{p l}-V_{1}}{R_{p l}}+C_{p l} \frac{d V_{p l}}{d t}=0$

$$
\begin{aligned}
& \frac{V_{p l}-V_{1}}{R_{p l}}=C_{1} \frac{d V_{1}}{d t}+\frac{V_{1}-V_{2}}{R_{1}} \\
& \frac{V_{1}-V_{2}}{R_{1}}=C_{2} \frac{d V_{2}}{d t}+\frac{V_{2}}{R_{2}}
\end{aligned}
$$

[15] Nodal analysis is the technique by which the sum of the cur-rents flowing to (or from) each node is set to zero. For example (6) states that the current flowing from the node labeled $\mathrm{V}_{\mathrm{pl}}$ through $\mathrm{R}_{\mathrm{pl}}$ plus the current flowing through $C_{\mathrm{pl}}$ to the reference (ground) node is zero (see Fig. 2). Equations (7) and (8) result from the application of nodal analysis in Fig. 2 at the nodes labeled $\mathrm{V}_{1}$ and $\mathrm{V}_{2}$, respectively Model results shown in this work were obtained by solving (6)-(8) numerically, using the software package MATLAB [17].Transient conditions begin when switch $S_{1}$ in Fig. 2 is closed [this corresponds to the opening of the injector valve shown in Fig. 1(b)]. Note that just before $S_{1}$ is closed, $\mathrm{V}_{\mathrm{pl}}$ (analogous to the remote plenum pressure) and $\mathrm{V}_{1}$ (analogous to the local plenum pressure) are both equal to the value $\mathrm{V}_{0}$. Initial conditions for $\mathrm{V}_{\mathrm{pl}}$ and $\mathrm{V}_{1}$ indicate that capacitors $\mathrm{C}_{\mathrm{pl}}$ and $\mathrm{C}_{1}$ are fully charged at are fully charged at time zero, which signifies the remote and local plenums being at a set initial pressure prior to opening of the injector. The solution to (6)-(8) requires a determination of the values of $R_{1}, R_{2}$ and $R_{p l}$ these values can be found from calculations based on empirical correlations for "resistance to gas flow" through simple fittings or measured FIG data for a particular system. Calculation of resistance using the first method is not realistic in our work since the resistance of the fuel injector is difficult to approximate accurately due to its complex geometry [see Fig. 1(b)]. The second method is tractable and more accurate. The key to measuring the resistances from FIG data is in designing experiments where certain variables are eliminated. For example, consider the time rate of rise of $V_{2}$ just after switch $S_{1}$ is closed

$\frac{d V_{2}}{d t, t=0}=\frac{V_{0}}{C_{2} R_{1}}$

Equation (9) results from (8) when $\mathrm{V}_{1}$ and $\mathrm{V}_{2}$ are set to their $\mathrm{t}=0+$ values of $\mathrm{V}_{0}$ and 0 , respectively. In (9), R1 is the only unknown variable assuming the initial rate of rise of $V_{2}$ is measured with the FIG. Once $R_{1}$ is found from (9), $R_{p l}$ can be found by isolating the vacuum pumps by closing the gate valve, thereby setting $\mathrm{R}_{2}$ to $\infty$ - Under these conditions $\mathrm{R}_{\mathrm{pl}}$ is the only unknown parameter, and its value can be found by fitting the model to the FIG data, for example, by selecting $\mathrm{R}_{\mathrm{pl}}$ such that the maximum pressure of the model matches the maximum pressure from the FIG data. Once $\mathrm{R}_{1}$ and 
$\mathrm{R}_{\mathrm{pl}}$ are determined for a particular gas, $\mathrm{R}_{2}$ can be obtained from a fit for open gate valve data. The resistor values found in this work for air and acetylene are listed in Table I.

\section{RESULTS AND DISCUSSION}

\section{A. Model Verification}

The model was validated on a series of runs with varying conditions, for both air and acetylene. The major parameters varied were

1) duration of the gas pulse;

2) type of injected gas (air versus acetylene);

3) The state of the vacuum pump gate valve (open versus closed).

Runs with the gate valve closed allowed for testing the versatility of the model, helped determine resistance values, and pro-vided the means for achieving higher pressures in the reactor in subsequent deposition experiments. Filling the remote and local plenums with room air set the conditions for some runs. For other runs, acetylene was supplied from a gas cylinder via a pressure regulator. The acetylene pressure was slightly above atmospheric pressure to prevent contamination of acetylene by air. Table II describes the conditions for these runs Fig. 3(a)-(c) shows comparisons between the model results and data from runs Air1, Air2, and Ac1, respectively (see Table II). At time zero in Fig. 3, the injector was energized with $12 \mathrm{~V}$ dc, but the pressure does not start rising until about $t=2 \mathrm{~ms}$ due to the injector "dead time." The circuit model in Fig. 2 has no "dead time" and the instant $S_{1}$ closes corresponds to the instant that the valve in Fig. 1(b) opens. Several other features in Fig. 3 are noteworthy. First is the apparent transition in the rate of pressure increase that is ob-served at about $t=10 \mathrm{~ms}$ for all runs in Fig. 3. This transition is due to the presence of the small local plenum, which is the unshaded region labeled in Fig. 1(b). As the injector valve opens, the gas expands into the reactor and the reactor pressure increases rapidly at the expense of a sharp drop in pressure in

TABLE I

ANALOGOUS ELECTRICAL AND GAS FLOW PARAMETERS

\begin{tabular}{|c|c|c|c|}
\hline $\begin{array}{l}\text { Circuit } \\
\text { Symbol in } \\
\text { Fig. } 2\end{array}$ & Electrical value for this work & Analogus Gas Flow Term & $\begin{array}{c}\text { Gas Flow Value for This } \\
\text { Work }\end{array}$ \\
\hline $\mathrm{V}_{\mathrm{o}}$ & 811 or $765 \mathrm{v}$ & $\begin{array}{l}\text { Initial pressure in the local } \\
\text { and remote plenums }\end{array}$ & 811 or 765 Torr \\
\hline $\mathrm{V}_{\mathrm{pi}}$ & Varies with time & $\begin{array}{l}\text { Pressure in the remote } \\
\text { plenum }\end{array}$ & Varies with time \\
\hline $\mathrm{V}_{1}$ & Varies with time & $\begin{array}{c}\text { Pressure in the local } \\
\text { plenum }\end{array}$ & Varies with time \\
\hline $\mathrm{V}_{2}$ & Varies with time & Pressure in the reactor & Varies with time \\
\hline $\mathrm{R}_{\mathrm{pi}}$ & $80 \mathrm{~K} \Omega\left(\right.$ forC $\left._{2} \mathrm{H}_{2}\right), 75 \mathrm{~K} \Omega$ (for air) & $\begin{array}{l}\text { Resistance to flow in feed } \\
\text { pipe connecting remote } \\
\text { and local }\end{array}$ & $\begin{array}{c}82 \mathrm{~s} / \mathrm{m}^{3}\left(\text { for } \mathrm{C}_{2} \mathrm{H}_{2}\right) \\
72 \mathrm{~s} / \mathrm{m}^{3} \text { (for air) }\end{array}$ \\
\hline $\mathrm{R}_{1}$ & $15 \mathrm{~K} \Omega\left(\right.$ for $\left.\mathrm{C}_{2} \mathrm{H}_{2}\right), 10 \mathrm{~K} \Omega$ (for air) & $\begin{array}{l}\text { Resistance of the injector } \\
\text { nozzle }\end{array}$ & $\begin{array}{c}13 \mathrm{~s} / \mathrm{m}^{3}\left(\text { for } \mathrm{C}_{2} \mathrm{H}_{2}\right) \\
11 \mathrm{~s} / \mathrm{m}^{3} \text { (for air) } \\
\end{array}$ \\
\hline $\mathrm{R}_{2}$ & $3 \mathrm{~K} \Omega\left(\right.$ forC $\left._{2} \mathrm{H}_{2}\right), 6 \mathrm{~K} \Omega$ (for air) & $\begin{array}{c}\text { Resistance simulating } \\
\text { vacuum pumps }\end{array}$ & $\begin{array}{c}3 \mathrm{~s} / \mathrm{m}^{3}\left(\text { for } \mathrm{C}_{2} \mathrm{H}_{2}\right) \\
6 \mathrm{~s} / \mathrm{m}^{3} \text { (for air) }\end{array}$ \\
\hline $\mathrm{C}_{\mathrm{pi}}$ & Varies, $34 \mu \mathrm{F}$ to $\infty$ depending on setup & $\begin{array}{l}\text { Volume of the remote } \\
\text { plenum }\end{array}$ & $\begin{array}{c}\text { Varies: } 3.2 \times 10^{-3} \mathrm{~m}^{3} \text { to } \infty \\
\text { depending on setup }\end{array}$ \\
\hline $\mathrm{C}_{1}$ & $0.12 \mu \mathrm{F}$ & $\begin{array}{l}\text { Volume of the local } \\
\text { plenum }\end{array}$ & $1.2 \times 10^{-7} \mathrm{~m}^{3}$ \\
\hline $\mathrm{C}_{2}$ & $12,280 \mu \mathrm{F}$ & Reactor volume & $1.24 \times 10^{-2} \mathrm{~m}^{3}$ \\
\hline
\end{tabular}

TABLE II

CONDITIONS FOR FAST IONIZATION GAUGE MEASUREMENTS

\begin{tabular}{|c|c|c|c|c|}
\hline Run Identification & Gas & Remote Plenum & Gate valve & $\begin{array}{c}\text { Duration of Gas } \\
\text { pulse }\end{array}$ \\
\hline
\end{tabular}




\begin{tabular}{|c|c|c|c|c|}
\hline Air1 & Air & 0 psig (760 Torr) & Open & 47 milliseconds \\
\hline Air2 & Air & 0 psig $(760$ Torr $)$ & Closed $\left(\mathrm{R}_{2}=\infty\right)$ & 47 milliseconds \\
\hline AC1 & Acetylene & $1 \mathrm{psig}(815$ Torr $)$ & Open & 24 milliseconds \\
\hline
\end{tabular}

the local plenum. Meanwhile, gas from the remote plenum starts entering. the local plenum via the feed line. After a quick initial discharge of the local plenum, quasi steady flow is established between the remote plenum and the reactor. For Fig. 3(a) and (b) with the gate valve open, as the rate of gas injection approaches the rate of pump down, the pressure curves will tend to flatten as time progresses. At larger times, provided there is an infinite remote plenum volume, the pressure would reach a steady state value. However, since the pulse duration in the present experiment was short (less than $50 \mathrm{~ms}$ ), the steady state between pump-down and injection was not established for these measurements. The model shows that it is not efficient to achieve pressures higher than about $30 \mathrm{~m}$ Torr in the reactor by increasing the injector pulse duration with the gate valve open since the vacuum pump is continually removing gas molecules from the reactor. As shown in Fig. 3(b), it is more efficient to close the gate valve if high pressures are desired. Another interesting feature in Fig. 3(a) and (c) are the pump-down regimes. In the Air1 run, Fig. 3(a), the injector valve closes after $48 \mathrm{~ms}$ and gas is pumped out of the reactor. The model does not predict this section of the curve well. Two possible explanations for this are overload of the pump and nonlinearity of the pump-down time constant [5]. Overload is a phenomenon where the diffusion pump speed drops drastically when pressure is too high, because the maximum mass flow capacity of the pump has been reached.

Variation in pumping time constant occurs because of initial adsorption of molecules at the walls of the pump, and the subsequent desorption which slows down the pumping process.
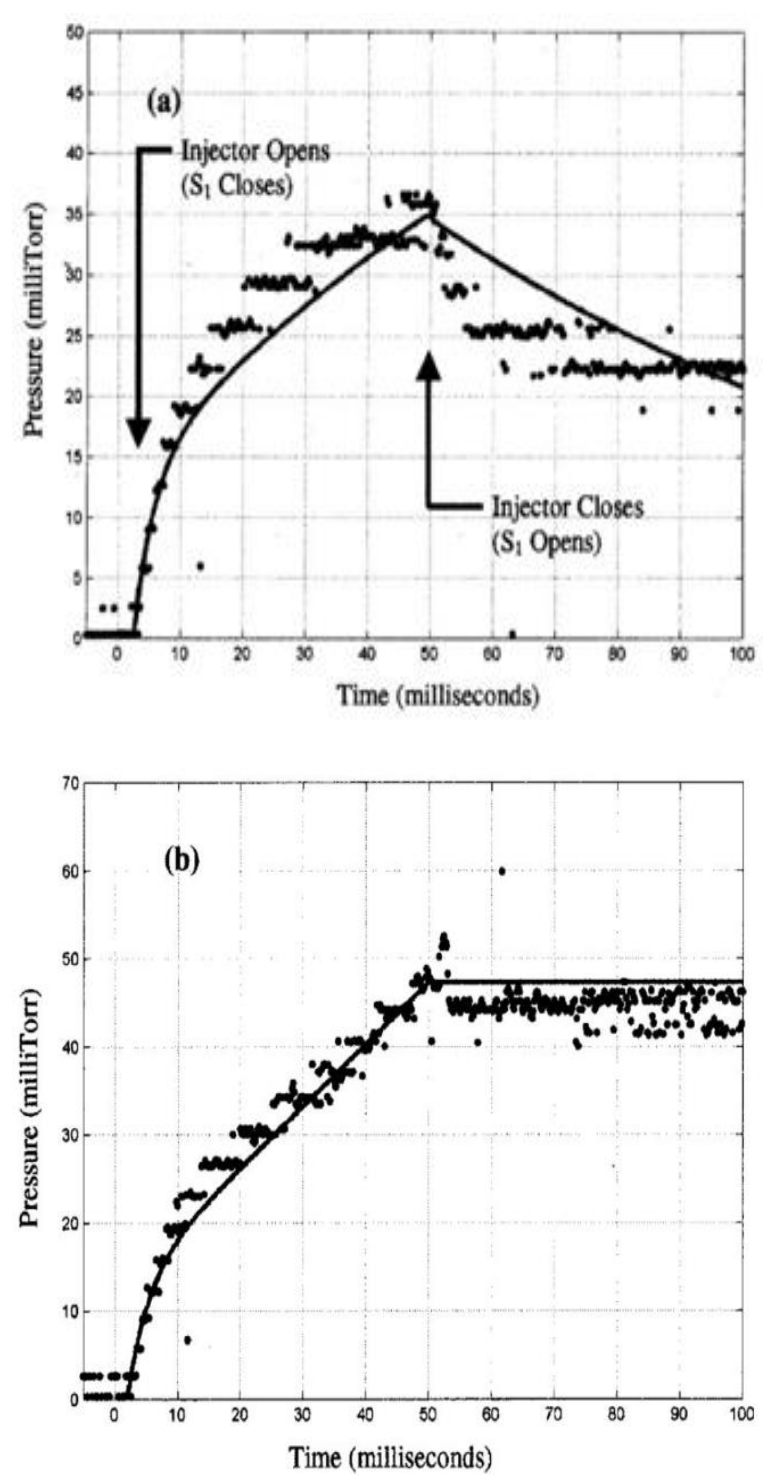


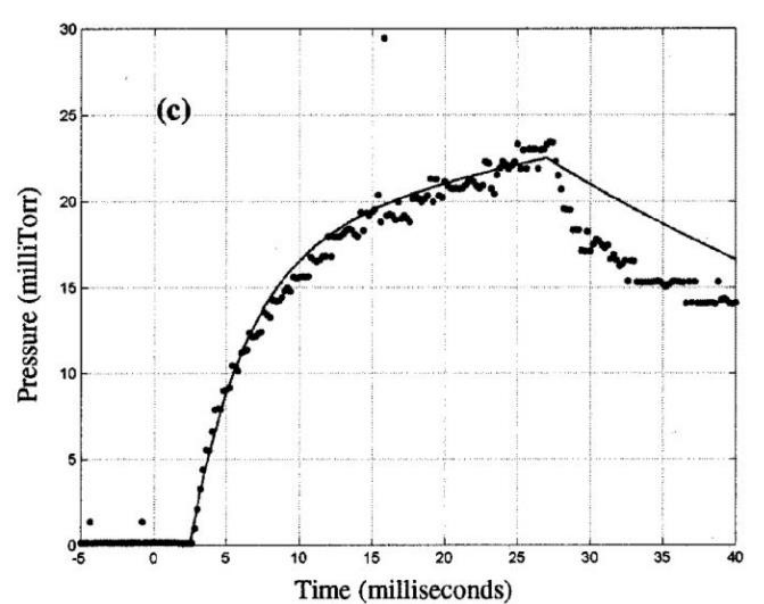

Fig.3. Comparison of model and FIG data for (a) Air1 run, (b) Air2 run, and (c) Ac1 run. See experimental conditions in Table II. The solid lines are predicted pressure from the model while dots are measured pressure from the FIG

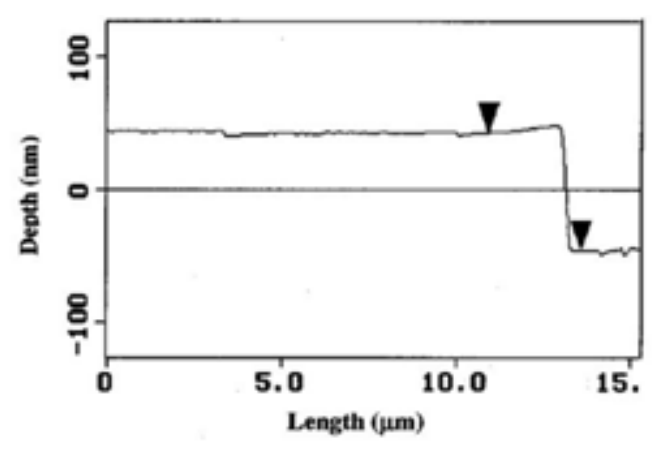

Fig. 4. AFM cross sectional view of the film scratch. Vertical distance between the two arrowheads is $88 \mathrm{~nm}$

\section{B. Model Applied to an Experiment}

The model described and validated above was also used in an experiment to relate preplasma pressure in the reactor to the measured deposition rate of plasmapolymerized acetylene Deposition rate was derived from thickness measurements obtained by making a scratch in the film (which was on $\mathrm{SiO}_{2}$ substrate) and scanning the scratched region with a profilometer and an atomic force microscope (AFM). Fig. 4 shows a typical cross sectional view obtained with the AFM.

Fig. 5(a) and (b) show the variation of deposition rate and the deposition rate efficiency with reactor monomer pressure prior to plasma initiation. Pressure values associated with the data points in Fig. 5 were obtained from the model shown in Fig. 2. The appropriate pressure value was obtained by knowing the time at which the RF energy was injected to initiate plasma conditions. Timing of the RF energy injection was obtained from an oscilloscope that monitored "voltage input" to the monomer injector in Fig. 1(b) and current through the RF coil. Curves such as the solid lines in Fig. 3 were used to obtain the appropriate pressure value for each of the data points in Fig. 5. Triangles in Fig. 5 represent runs with the vacuum pump gate valve closed prior to injection of monomer gas and circles represent runs with the gate valve open. All deposition rate values in Fig. 5(a) were obtained by measuring film thickness after 50 runs and dividing the total thickness by 50 . Two measurements were made for each deposition rate data point and standard deviation between the two measurements was calculated. Standard deviation was randomly scattered around an average value of $3.5 \AA$ per run, which was taken as the error bar shown in Fig. $5(\mathrm{a})$.

The solid line in Fig. 5(a) represents the "ideal" deposition rate, attainable if all the monomer between injector and substrate at time zero (start of RF energy injection) would be converted into reactive species and would travel in a straight line toward the substrate where it would be deposited. An expression for this condition is

$\rho_{\text {Solid }} d_{\text {Solid }}=\rho_{\text {Gas }} d_{\text {Gas }}$

Whera

$\rho_{\text {Solid }}$ mass density of the solid film;

$\mathrm{d}_{\text {Solid }}$ thickness of solid film deposited per run

$\rho_{\text {Gas }}$ mass density of the gas.

$\mathrm{d}_{\text {Gas }}$ thickness of the gas region between injector and substrate;

The monomer pressure in Pascals, $p$, is defined by the ideal gas law as

$\rho_{\text {Gas }}=M_{\text {Gas }}\left(\frac{\rho}{K T}\right)$

Where

$M_{\text {Gas }}$ is Mass of the gas molecule

$\mathrm{K}$ is Boltzmann's constant

$\mathrm{T}$ is temperature in kelvin.

Substituting for $\rho_{\text {Gas }}$ in (10) and solving for $d_{\text {SOLID }}$ we obtain

$d_{S O L I D}=\left(\frac{M_{G a S}(\rho / K T)}{\rho_{S O L I D}}\right) d_{G A S}$ 
Converting $\mathrm{d}_{\text {Solid }}$ to the ideal deposition rate in angstroms per run, $\mathrm{D}_{\text {IDEAL, }}$ and expressing $\rho$ in units of millitorr gives

$\mathrm{D}_{\text {IDEAL }}[\AA /$ run $]=2.46 \rho[$ millitor $]$

where the values of $M_{G a s}, K, T$, , $\rho_{\text {Solid }}$ and $\mathrm{d}_{\mathrm{Gas}}$, were equal to $4.316 \times 10^{26} \mathrm{~kg}, 3.18 \times 10^{-23} \mathrm{~J} / \mathrm{K}, 300 \mathrm{~K}, 2260$ $\mathrm{kg} / \mathrm{m}^{3}$, and $0.40 \mathrm{~m}$, respectively. The value for $M_{\text {Gas }}$ is for acetylene, $\mathrm{d}_{\mathrm{Gas}}$ was measured from the experiment and $\rho_{\text {Solid }}$ is consistent with Goyal [18] and Zou et al. [19]. The ideal deposition rate described in (13) is not attainable due to inefficiencies in monomer dissociation and losses to the walls. Equation (13) sets an upper bound for plausible measured deposition rates. It is plotted as the solid line in Fig. 5(a). Deposition rate efficiency, shown in Fig. 5(b), was obtained as a ratio of observed deposition rate to the "ideal" deposition rate [solid line in Fig. 5(a)]. The maximum deposition rate is seen to occur at an equivalent static pressure of about 25 millitorr. The deposition rate decreases at pressures above this value. Such a relative maximum in deposition rate versus pressure has been previously observed [1].
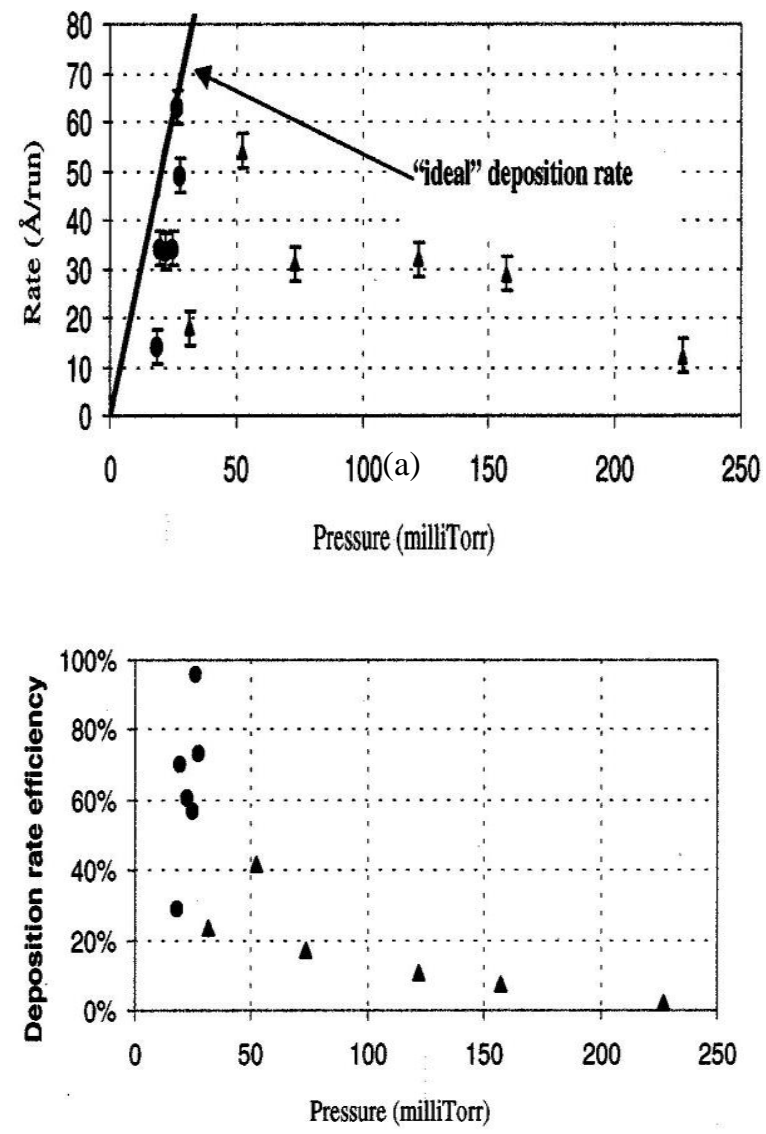

doi: 10.32622/ijrat.76201961
Fig.5.Variation of deposition rate as a function of acetylene pressure: (a) Deposition rate versus pressure and (b) Deposition rate efficiency versus pressure. Triangles represent runs with the vacuum pump gate valve closed prior to injection of gas and circles represent runs with the gate valve open. The horizontal axis represents reactor monomer pressure that existed just before plasma conditions were initiated.

Fig. 6 shows the final radical axial profile in the reactor after the passage of the plasma plug. After the initial increase in radical concentration inside the RF coil region, radical concentration decreases because dissociation rate decreases with temperature. As stated earlier, the final radical concentration profile is used as an initial condition for the diffusion model. Solution of the diffusion model yields radial and axial deposition rate profiles.

Fig. 7 presents a comparison between predicted radial and axial deposition rate profiles and collected data. As can be seen from Fig. 7 the model agrees well with the measured data. However, in order to get such an agreement, several plasma parameters had to be adjusted.

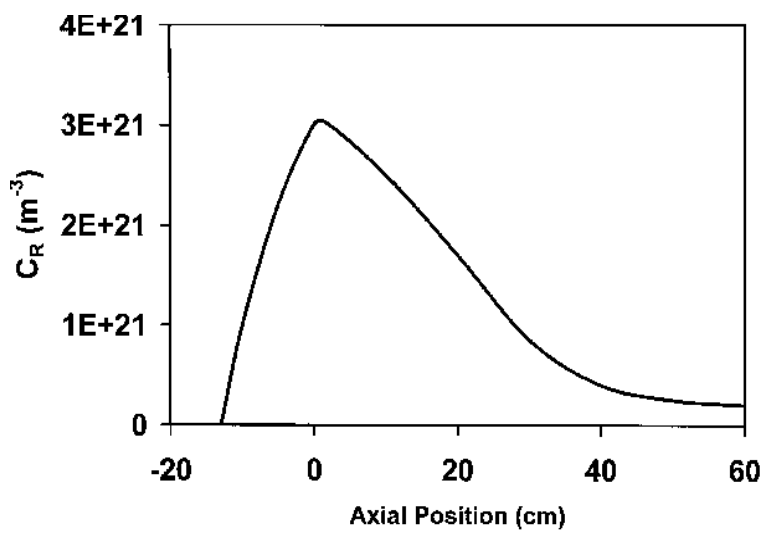

Fig. 6. Final radical axial profile 
International Journal of Research in Advent Technology, Vol.7, No.6, June 2019

E-ISSN: 2321-9637

Available online at www.ijrat.org

(a)

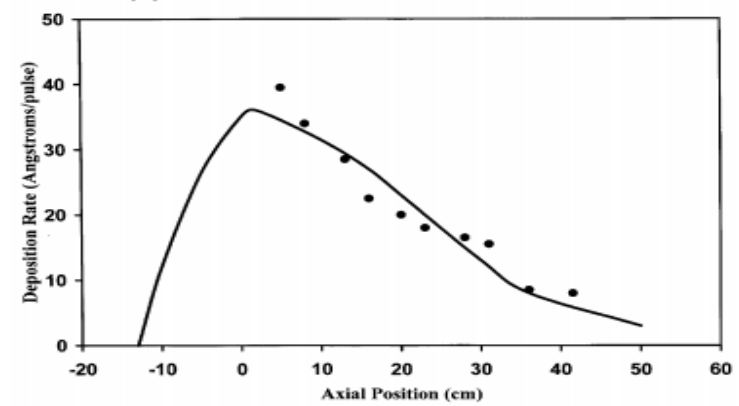

(b)

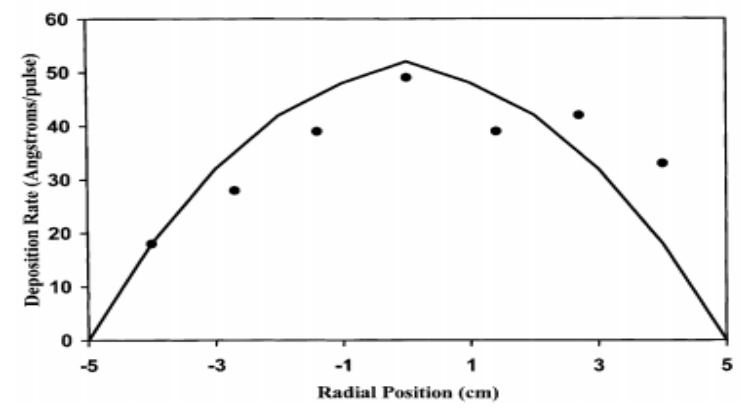

Fig.7. a Aniline axial deposition rate profile along the reactor wall. b. Aniline radial deposition rate profile at axial location $x=20 \mathrm{~cm}$. Dots are measured data points, while the lines are model predictions.

\section{CONCLUSIONS}

Preplasma pressure profiles are difficult to measure in pulsed plasma reactors due to short time scales. An electrical analog model has been developed that is useful at predicting these preplasma pressure transients. The transient pressure model has been verified with FIG measurements. Using the transient pressure model, it was determined that in order to achieve higher pressures (above about 30 millitorr) in the reactor within reasonable pulse duration, the vacuum pump gate valve should be closed just before the start of monomer injection. The transient pressure model was utilized to experimentally study deposition rate as a function of pressure for acetylene monomer. The maximum deposition rate of $62 \AA /$ run for this device was found to be at a pressure of about 25 millitorr. Further pressure increase beyond this resulted in deposition rate decrease. Electron concentration, electron temperature and dissociation cross-section were adjusted to obtain good agreement with the data. The model provides a new way to analyze plasma polymerization and it gives a useful insight into the pulsed deposition process.

\section{REFERENCES}

[1] M. Chen, T. C. Yang, and Z. G. Ma, "Plasma polymerization of styrene with controlled particle energy," J. Polymer Sci. A: Chem., vol. 36, pp. 1265-1270, 1998.

[2] J. H. Lee, D. S. Kim, Y. H. Lee, and B. Farouk, "Effects of rf power on plasma phase reactions and film structure in deposition of a-C:H by styrene/argon discharge," J. Electrochem. Soc., vol. 143, no. 4, pp. 1451-1458, Apr. 1996.

[3] Y. M. Tsai, U. R. Aggarwal, F. J. Boerio, D. B. Zeik, S. J. Clarson, W. J. Van Ooij, and A. Sabata, "Spectroscopic characterization of plasmapolymerized films of ethane, ethylene, and acetylene on metal substrates," in Proc. Amer. Chem. Soc. Symp. Plasma Deposition Polymeric Thin Films: Chem., Characterization, Applicat., Mar. 28-29, 1993, 1994, pp. 3-27,.

[4] S. A. Letts, R. C. Cook, P. Welch, R. McEachern, and E. Fearon, "Effect of process parameters on plasma polymer surface finish," Polymer Preprints, vol. 34, no. 1, pp. 677-678, Mar. 1993.

[5] C. H. Courtney, B. C. Smith, and H. H. Lamb, "Remote plasma-enhanced chemical vapor deposition of $\mathrm{SiO}$ using $\mathrm{Ar} / \mathrm{N} \mathrm{O}$ and $\mathrm{SiH}$," J. Electrochem. Soc., vol. 145, no. 11, pp. 3957-3962, Nov. 1998.

[6] C. Wang and R. G. Cheng, "Effect of plasma pressure on the properties of a-Si : H," Philosophical Mag. B, vol. 53, no. 3, pp. 183-191, 1986.

[7] H. Yasuda, Plasma Polymerization. Orlando, FL: Academic, 1985, ch. 8 and 9.

[8] H. Kobayashi, A. T. Bell, and M. Shen, "Formation of an amorphous powder during the polymerization of ethylene in a radio-frequency discharge," J. Appl. Polymer Sci., vol. 17, pp. 885-892, 1973.

[9] J. H. Leck, Pressure Measurement in Vacuum Systems, 2nd ed. London, U.K.: Chapman \& Hall, 1964.

[10]P. D. Pedrow, A. M. Nasiruddin, and R. Mahalingam, "Unsteady adiabatic isentropic expansion of gas into vacuum from a toroidal puff valve," J. Appl. Phys., vol. 67, pp. 6109-6113, May 1990.

[11]P. D. Pedrow, L. V. Shepsis, R. Mahalingam, and M. A. Osman, "Computer controlled pulsed PECVD reactor for laboratory scale deposition of plasma polymerized thin films," in Proc. Electroactive Polymers Symp. Materials Research Soc., 1999, vol. 600, pp. 325-331. 


\section{International Journal of Research in Advent Technology, Vol.7, No.6, June 2019 \\ E-ISSN: 2321-9637 \\ Available online at www.ijrat.org}

[12]M. Ueda, Intense ion beam from a magnetically insulated diode with an active anode source, Cornell Univ., Ithaca, NY, pp. 307-309, 1986.

[13] J. T. Tate and P. T. Smith, "The efficiencies of ionization and ionization potentials of various gases under electron impact," Phys. Rev., vol. 39, pp. 270-277, Jan. 1932.

[14]F. Nakao, "Determination of the ionization gauge sensitivity using the relative ionization cross section," Vacuum, vol. 25, no. 9/10, pp. 431-435, 1975.

[15]H. Tanaka, H. Toyoda, H. Sugai, Jpn. J. Appl. Phys. Part 1, 37(1998). 5053.

[16] C.B. Labelle, S.M. Karecki, R. Reif, K.K. Gleason, J. Vac. Sci.Technol. A 17 Ž1999. 3419.

[17] C.B. Labelle, K.K. Gleason, J. Vac. Sci. Technol. A 17 (1999). 445 .

[18] K. O. Goyal, "Studies on preparation and characterization of thin acetylene plasma polymer films in a pulsed PECVD reactor," M.S. thesis, Chem. Eng. Dept., Washington State Univ., Pullman, p. 162, 1995.

[19] The Math Works, Inc., , Natick, MA.

[20] M.A. Lieberman, A.J. Lichtenberg, Principles of Plasma Discharges and Materials Processing, Chapters 3,8, Wiley-Inter science, New York, 1994. 